\title{
Weakness of will, akrasia, and the neuropsychiatry of decision making: An interdisciplinary perspective
}

\author{
Annemarie Kalis \\ Universiteit Utrech, Utrecht, The Netherlands \\ Andreas MoJZisch \\ Georg-August-Universität Göttingen, Göttingen, Germany \\ T. SOPHIE SCHWEIZER \\ Vrije Universiteit Amsterdam, Amsterdam, The Netherlands \\ AND \\ STEFAN KAISER \\ Ruprecht-Karls-Universität Heidelberg, Heidelberg, Germany
}

\begin{abstract}
This article focuses on both daily forms of weakness of will as discussed in the philosophical debate (usually referred to as akrasia) and psychopathological phenomena as impairments of decision making. We argue that both descriptions of dysfunctional decision making can be organized within a common theoretical framework that divides the decision making process in three different stages: option generation, option selection, and action initiation. We first discuss our theoretical framework (building on existing models of decision-making stages), focusing on option generation as an aspect that has been neglected by previous models. In the main body of this article, we review how both philosophy and neuropsychiatry have provided accounts of dysfunction in each decision-making stage, as well as where these accounts can be integrated. Also, the neural underpinnings of dysfunction in the three different stages are discussed. We conclude by discussing advantages and limitations of our integrative approach.
\end{abstract}

Most of us do not always do what, in our own eyes, we judge to be best. Imagine Bessie, who is enjoying a holiday after a period of hard work. In her own eyes, she has reason to do all kinds of interesting things. She has been looking forward to this holiday for a long time and there are plenty of things that she could do. But instead, to her own distress, all she does is lie on the sofa and watch television. For most of us, examples like this will sound disturbingly familiar. Even if not everyone has the difficulties Bessie has, most of us will recognize the general pattern: taking another slice of cake even though you planned not to, deciding to donate more money to charity but never getting around to actually doing it, and so on. The possibilities are endless. These examples have a common structure: You hold a certain judgment about what you think is worthwhile doing, but ultimately you do something else or nothing at all.

In this article, we discuss such examples as cases of dysfunctional decision making. In everyday life, our decisions sometimes do not match our consciously held value judgments, or our actions do not match our decisions.
Such phenomena are often attributed to a weakness of will. This term already suggests a certain explanation: Our will is not strong enough for us to translate our values into action. Underlying this explanation is the idea that the will is a power that sides with our value judgments and counters the force of opposing motivational influences. However, there is another influential conception of will that would not allow for such an explanation: Many of us understand the will to be the general power that leads us to action. On such accounts, the concept of will is often used interchangeably with that of volition (Frankfurt, 1988; Metzinger, 2006). When the will is understood to be a general power, it does not make sense to explain acting against your values as being due to weakness of will. For this reason, philosophical discussions on acting against your own value judgments often replace the term weakness of will with akrasia, which does not depend on a specific understanding of will. Akrasia is a Greek term first found in the writings of Aristotle; the term could be translated as a lack of self-control (Aristotle, trans. 2002; Mele, 1987). Aristotle understood akrasia to be a character trait. People 
are akratic if they are overcome by desires or appetites in cases in which most other people would not succumb. Because of the presence of desire, the agent's knowledge of the good does not operate as it should. The fact that one has knowledge of the good can be derived from one's having made a certain value judgment; nevertheless, this knowledge is not translated into action.

The current philosophical debate on akrasia focuses on two questions. The first question centers on whether it is, in fact, possible to act against what you think is best (Davidson, 2001; Hare, 1963; Watson, 1977). In other words, is it really warranted to claim that Bessie thinks it best to spend her holiday doing all kinds of interesting things? Or has she just changed her mind, now actually thinking that it is best to stay on the couch? This closely relates to discussions about what it actually means to think it best to do something (Arpaly, 2000; McIntyre, 1990). It has been argued that it could sometimes be highly adaptive to act against your own judgment (see Ainslie, 2001; Arpaly, 2000). However, even in cases where going against your own judgment is adaptive, it is still subjectively irrational; the agent experiences a conflict between his own values and his behavior. It is such conflicts we are concerned with here. The second focus of philosophical discussion is how such actions should be explained (Ainslie, 2001; Mele, 1987; Perkins, 2002; Stroud \& Tappolet, 2003). It is generally acknowledged that akrasia is a general concept that covers a wide variety of irrational actions. For philosophical attempts to categorize different kinds of akratic actions, see A. Oksenberg Rorty (1988) or Pettit and Smith (1993).

In the philosophical discussion, akratic actions are usually contrasted with psychopathological phenomena, such as addiction and compulsion. The idea is that akratic behavior is free, whereas pathological behavior is not (Kennett \& Smith, 1994; Mele, 1987; Smith, 2003). We will not try to do justice to the immense debate about free action, but we will take another perspective: Instead of discussing daily irrationalities and neuropsychiatric phenomena in different terms, integrating them in a common theoretical framework can lead to fruitful insights that could inform discussions in both the philosophical and the psychiatric domain. Our goal is to review different kinds of dysfunctional decision making described in both philosophy and psychiatry and to show how they can be organized within a common theoretical framework. Of course, examples like Bessie's allow for a lot of different explanations. We do not claim to provide an exhaustive inventory of explanations. What we hope to provide here are tools that allow one to identify the most plausible explanations for different kinds of decision-making problems. We will be able to develop only a highly general outline of such a common framework; nevertheless, we hope to show that such a framework can help to identify promising directions for future interdisciplinary research.

The framework that we propose divides the decisionmaking process into three different stages: option generation, option selection, and action initiation (see Figure 1). A central idea of this approach is that observed dysfunctions in behavior may be caused by dysfunctions in any of the three decision-making stages. To illustrate, consider Bessie lying on the sofa and watching a boring TV show, even though she would rather do something interesting. This behavior may be due to the fact that (1) Bessie cannot come up with any options for action that she considers worthwhile (Stage 1: option generation), (2) Bessie has problems deciding from among several options (Stage 2: option selection), or (3) Bessie has decided on one choice option, but still does not act on her decision (Stage 3: action initiation).

Our framework builds on and expands existing sequential models of decision making and action (Ernst \& Paulus, 2005; Heckhausen \& Gollwitzer, 1987). We try to show that both the daily irrationalities discussed in the debate on akrasia and the dysfunctions that are the focus of research in psychopathology can be differentiated into distinct dysfunctions in one or more of those stages (see Figure 2). We will investigate correspondences between psychopathologies of decision making and akrasia on a phenomenological level, and we will also identify possible underlying neuropsychological correlates of function and dysfunction in the different stages. Relating dysfunctions on a phenomenological level to those on the neuropsychological level allows us to develop an empirical research program employing psychopathological rating scales and neuropsychological tests (see Tables 1 and 2, on p. 413). We are aware that these instruments have been developed in other contexts and that further development will be needed to address the specific dysfunctions postulated in the model.

Of course there are complex relationships to other constructs used in psychology and psychopathology. We have

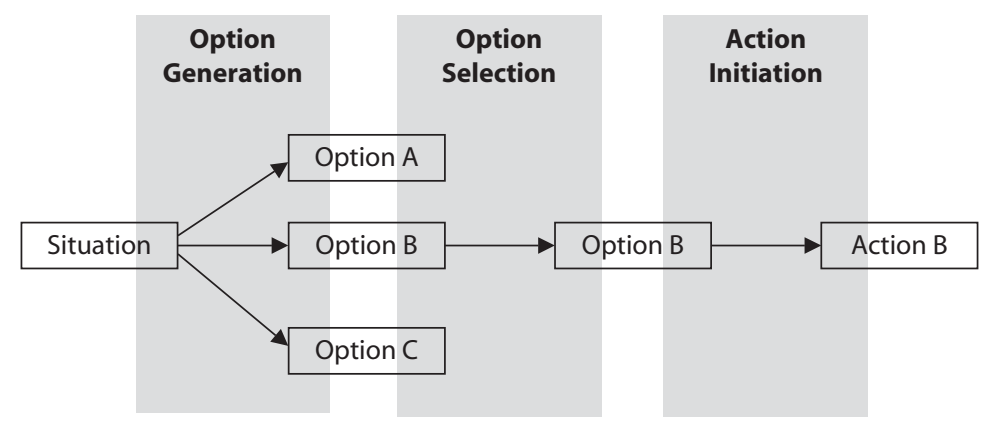

Figure 1. Stages of decision making in our model. 


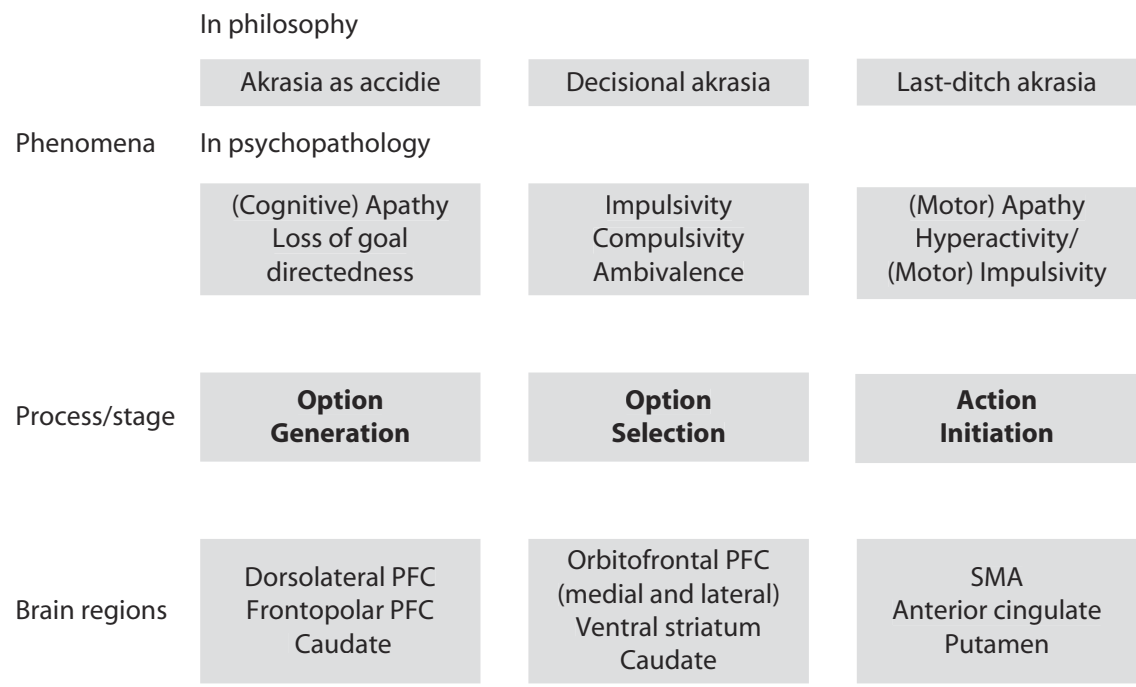

Figure 2. Three levels of explanation are distinguished in our model: (1) phenomena, in philosophical or psychopathological terms; (2) processes or stages of decision making; and (3) associated brain regions.

chosen to discuss only those concepts that can be specifically related to one or more of the stages in our model. An example would be hyperbolic discounting, which we will describe as a concept specifically related to option selection (Ainslie, 2001, 2006). Broader relevant concepts include motivation and volition, which we will show to be related in specific ways to the stages of our model. In contrast, we have decided not to include constructs that are believed to play a role in all stages of the model. This pertains mainly to concepts that assume some underlying driving force, such as energy and drive, but also to certain more specific concepts, such as ego depletion (Muraven \& Baumeister, 2000).

At present, the empirical base for our arguments mainly consists of studies on individual decision making. We acknowledge the huge importance of social decision making, but any discussion of such decision making is beyond the scope of the present article.

\section{STAGES OF DECISION MAKING}

There are several prominent models describing different phases or stages of decision making for action. Ernst and Paulus (2005) discussed three distinct stages of decision making: (1) the assessment and formation of preferences among several possible options, including the process of editing the options (e.g., ignoring the least attractive options); (2) the selection and execution of an action, including the inhibition of alternative courses of actions; and (3) the evaluation of the outcome of the action.

Similarly, in their Rubicon model of action phases, Heckhausen and Gollwitzer (1987) posited that people go through four action phases that are proposed to differ in terms of the tasks that need to be addressed before the individual is able to move on to the next phase. (1) In the predecisional phase, one weighs the pros and cons of his or her desires and wishes by evaluating the desirability of the expected outcomes and assessing the question of feasibility. The selection of an option for action marks the transition to (2) the postdecisional phase. In this phase, one plans the implementation of the chosen option by deciding where, when, and how he or she wants to act on the goal. (3) In the actional phase, the individual progresses toward the implementation of the goal by initiating goal-directed behaviors. (4) In the postactional phase, the achieved outcomes of the goal-directed behavior are evaluated by looking backward (i.e., how successfully did I perform the action?) and forward (i.e., what remains to be done to achieve the desired outcome?). According to Heckhausen (Heckhausen, 1991; Heckhausen \& Gollwitzer, 1987), the predecisional and postactional action phases are regarded as being motivational. Information processing during these phases is proposed to be open-minded and impartial, allowing the individual to draw conclusions impartially and make the best possible decisions. During the postdecisional planning phase and the actional phase, however, information processing is thought to be biased in favor of the chosen alternative. This is often referred to as a volitional orientation.

It should be noted, however, that several other ways of distinguishing motivation and volition have been proposed. For example, in philosophy, some have understood volition as being a specific kind of motivation (Frankfurt, 1988), others have identified volition with the concept of will (Metzinger, 2006), and still others have argued that volition is a superfluous concept (Stroud \& Tappolet, 2003). In this article, we will use Heckhausen's distinction as our starting point and mention contrasting interpretations where relevant.

When we compare our model to Heckhausen's (Heckhausen, 1991; Heckhausen \& Gollwitzer, 1987), two main differences are of importance. First, we will focus on the stages that are classically associated with akrasia in the philosophical literature - the stages prior to and including 
the initiation of the action (Mele, 1987; A. O. Rorty, 1988). This means that we have excluded the stage of monitoring during action execution and outcome evaluation. On the other hand, the hitherto neglected topic of option generation has been included. We decided to include the process of generating options for actions as a separate phase in our model because we propose that particular psychiatric phenomena are associated with this phase. Second, our stages do not correspond directly to the phases defined by Heckhausen, but rather to the transition points between these phases. This can be exemplified most easily by looking at his third and fourth stages. Option selection marks the transition between the predecisional phase and planning as the first postdecisional phase. Action initiation occurs in the transition between the two postdecisional phases (planning and action phase). Option generation is not included in the Heckhausen model, but we suggest that it marks the transition from a phase where no options are readily available to the predecisional phase, where deliberation on the best possible option occurs. According to Heckhausen's conceptions of motivation and volition, option generation would be most strongly related to motivation; action initiation would be a volitional phase. Option selection would occur between the motivational and volitional phases.

The term option has been used quite inconsistently. For the purpose of this article, we propose an option to essentially consist of two major components: a possible action (what executing the option would amount to) and the expected affective value associated with that action (see also Ernst \& Paulus, 2005). First, a cognitive-motor program contains the action, as well as its conditions, on a cognitive-motor level. Second, options also need to have an affective value, in order to motivate the agent to select and initiate an action. Previous accounts of action control have emphasized that representations of goals and representations of actions do not exist in isolation but are together represented as goal-action episodes (Schneider, 2006). The notion of a goal-action episode closely corresponds to the construct of option we use in this article.

In the following, we will introduce the different elements of our theoretical framework. We focus on option generation in particular, because this stage has been somewhat neglected by previous models. We will review how both philosophy and psychiatry have provided accounts of dysfunction in each decision-making stage and where these accounts overlap.

\section{Option Generation}

Most experimental research on decision making has been concerned with the selection and execution of existing options for action. But we know very little about where these options come from in the first place and about the mechanisms underlying option generation (Klein \& Wolf, 1998). This does not need to be a problem when investigating decision making in well-constrained experimental environments. However, a serious problem arises when approaching real-world complexity, where most decision situations are heavily underconstrained (Raab \& Johnson, 2007). The option generation stage consists of the pro- duction of possible actions and their values, depending on the situational constraints. Less constrained situations place a higher demand on the processes underlying option generation.

We propose a general framework for understanding the processes underlying the generation of options. This framework includes three main pathways to an option: (1) In constrained situations, the option can be directly given by the situation at hand. (2) With a certain expertise regarding the situation, the option can be retrieved from long-term memory. (3) In completely new situations, new options have to be generated. Obviously these three general pathways are not mutually exclusive and will necessarily interact in real-world situations.

As already mentioned, most decision-making research has focused on the first type of situations, where the options are given by the situation - that is, the task at hand. Research addressing the retrieval of options by persons with expertise for the situation has been conducted mainly in the fields of sports sciences and human-machine interactions (Klein \& Wolf, 1998; Raab \& Johnson, 2007). Here, option generation has been explicitly defined as the retrieval of an action program from long-term memory, based on the association strength between candidate options and the current situation (Raab \& Johnson, 2007). To our knowledge, no attempt has been undertaken to investigate this retrieval of an action program on a neuropsychological level. Note, however, that verbal fluency tasks that require fluent retrieval from long-term memory may be related to option generation (Lezak, Howieson, Loring, Hannay, \& Fischer, 2004). Although these tasks clearly do not require the generation of options for action, the self-organized retrieval of items from long-term memory with relatively few situational constraints (e.g., words beginning with "s") is likely to tap a component process of option generation. Activation of the left inferior frontal gyrus has consistently been observed in healthy subjects performing verbal fluency tasks (Costafreda et al., 2006).

Loosening constraints in tasks requiring action generation while keeping experimental control has been attempted through a number of ways. For example, Spence and colleagues instructed subjects to vary either the timing or the order of simple motor acts in a series of imaging experiments (Spence \& Parry, 2006). The comparison between free selection and stereotypic movement showed stronger activation of left prefrontal cortex during free selection, which is similar to that in the regions activated in fluency tasks. Variation in responses could be a promising way to measure option generation. However, it has to be kept in mind that these tasks mainly address the "when" of actions, not the "what." The actions are spontaneously generated in time, but the subject does not develop new options for action.

The generation of new options in unconstrained and unknown situations has not been explicitly addressed. However, it may be possible to draw from research on creativity and abstract problem solving. In the Torrance Tests of Creative Thinking, for example, fluency (next to flexibility and originality) is defined as one dimension of creative think- 
ing and refers to the number of ideas or alternate solutions to a problem one generates (Torrance, 1990). The so-called brick test, which is the best-known alternative-uses test in creativity research, also aims to measure one's capacity to generate options; it asks participants to generate as many possible uses for a brick as they can (Guilford, Christensen, Merrifield, \& Wilson, 1978). Experimental research on creativity has traditionally taken an interindividual differences approach, but recent research has more directly addressed putative neurocognitive underpinnings of novelty generation and creativity (Schweizer, 2006). Several brain imaging methods have already been employed to investigate brain activation during various creative tasks, as well as the relationship between creativity and cerebral blood flow at rest (Bechtereva et al., 2004; Chávez-Eakle, GraffGuerrero, García-Reyna, Vaugier, \& Cruz-Fuentes, 2007; Fink, Benedek, Grabner, Staudt, \& Neubauer, 2007). The results are far from consistent (implicating bilateral prefrontal cortex as well as left temporal cortex), which has supported the assumption that creativity is a highly heterogeneous concept (Dietrich, 2004). Although it may thus be possible to build on creativity research, the differences between creative cognition and option generation should not be neglected. Creative cognition is not about generating options that correspond best to one's values in a given situation, but about creating new and unusual options. In addition, many tests employed in creativity research do not require generation of options for action at all, but instead require generation of abstract items. As a result, tests that are developed to measure creativity are not directly suitable for measuring option generation, but can be thought to assess component processes and inform the development of option generation paradigms.

Option generation in unconstrained and unknown situations may be related also to the solving of ill-structured problems, which has been a long-standing area of research in the cognitive literature (Simon, 1973). A problem is understood as a combination of a start state and a goal state, so that problem solving requires finding the appropriate transformation. Real-world problems are thought to differ from most tasks in a variety of dimensions, but most importantly in the lack of constraints on the solution path. In their recent work, Goel and Vartanian (2005; Vartanian \& Goel, 2005) have defined a bilateral frontal network underlying hypothesis generation and a more specific role for the right inferior prefrontal cortex in lateral transformations (i.e., breaking away from a current state of affairs). A prominent role for the frontopolar cortex in the evaluation of internally generated information has also been discussed (Christoff \& Gabrieli, 2000). This type of problem-solving research is relevant for option generation because it focuses on the ill-structured nature of situations, but it has operated mostly on a cognitive level. As a result, the affective dimension that is characteristic of options for action has not received much attention.

\section{Option Selection}

The selection of options and the initiation of actions have been present in previous stage models of decision making and have recently been reviewed (Mostofsky \& Simmonds, 2008; Sanfey, Loewenstein, McClure, \& Cohen, 2006). Therefore, we will highlight only important topics that are of relevance to the study of akrasia and psychopathology. In option selection, the most relevant areas of research pertain to the coding of different parameters that affect a decision, such as expected value, risk, and uncertainty (Cardinal, 2006; Tobler, O'Doherty, Dolan, \& Schultz, 2007). There is now consistent evidence for the ventral striatum coding for expected reward value (Knutson \& Peterson, 2005; Tobler et al., 2007). In addition, there has been some debate about whether potential losses are represented in the same brain structures or whether a partially separable system, including the amygdala, is involved (Tom, Fox, Trepel, \& Poldrack, 2007; Yacubian et al., 2006). Uncertainty coding has been observed mainly in lateral frontal - particularly orbitofrontalareas (Huettel, Stowe, Gordon, Warner, \& Platt, 2006; Tobler et al., 2007).

One example of current research on option selection that is of special relevance to our topic is the field of intertemporal decision making - that is, the influence of a reward or punishment delay on option selection (Wittmann \& Paulus, 2008). Generally, the subjective value of rewards decreases (is discounted) with delay, according to a hyperbolic function where the slope of the function varies between individuals (Ainslie, 2001). Functional imaging studies have suggested that different neural systems are recruited for decisions involving immediate rewards and delayed rewards. For example, in one study, McClure, Laibson, Loewenstein, and Cohen (2004) measured neural activity while participants were given a series of choices between smaller/earlier rewards and larger/later rewards. The rewards participants could obtain were gift certificates ranging from US\$5 to US\$40. The earlier option always had a lower value than the later option. The two options were separated by a time delay of at least 2 weeks. In some choice pairs, the earlier option was available almost immediately (i.e., at the end of the scanning session). In other pairs, even the earlier option was available only after a delay. The imaging results suggested that two separate neuronal systems were involved in such decisions. Thus, parts of the lateral prefrontal cortex and posterior parietal cortex were engaged uniformly by the choices, irrespective of the delay. However, regions of the limbic system, including the paralimbic cortex, were preferentially activated by choices involving immediately available rewards. Moreover, the relative engagement of the two brain systems was directly associated with the participants' choices, with greater relative frontoparietal activity when participants decided on the larger/later options. These results have been interpreted by the authors as reflecting the operation of two fundamentally different brain systems: one that is responsible for reasoning and future planning and one that motivates impatient emotional choices. However, this interpretation of the data seems to be somewhat premature (see Ainslie \& Monterosso, 2004, for a critical discussion of this interpretation); hence, future research is needed to address this issue. 


\section{Action Initiation}

Action initiation involves different levels of cognitive and motor function. Action initiation on the simplest level pertains to the initiation of a self-paced motor act; the demands on motor planning increase with higher complexity of the action to be performed. Simple self-paced motor acts activate medial frontal areas including the pre-SMA (supplementary motor area) and the anterior cingulate cortex (Cunnington, Windischberger, Deecke, \& Moser, 2002; Seitz, Stephan, \& Binkofski, 2000). When more complex processing of context or planning is required, lateral prefrontal brain regions are also recruited (Seitz et al., 2000). Classically, a distinction between internally and externally guided movements is made; the former is thought to rely on medial frontal areas, including the preSMA (Passingham, 1995). In a recent fMRI study, the role of this region for representing intentions was emphasized (Lau, Rogers, Haggard, \& Passingham, 2004). Stimulation of the SMA and pre-SMA can lead not only to the initiation of motor behavior, but also to the experience of an urge to act (Fried et al., 1991). Despite the importance of these observations and the prominent role of these areas for action initiation, it has to be kept in mind that this is only one step in the sequence leading to voluntary action (see also Nachev, 2006, for a critical discussion).

The close relationship between action initiation and action inhibition has been identified as an important topic for cognitive neuroscience and psychopathology (Logan, Schachar, \& Tannock, 1997). Action inhibition has been an area of intense research in cognitive neuroscience. A key role for the right inferolateral prefrontal cortex has been consistently demonstrated (Aron, Robbins, \& Poldrack, 2004). However, it has also been argued that action inhibition recruits brain regions overlapping with action initiation - specifically, the pre-SMA (Simmonds, Pekar, \& Mostofsky, 2008).

Notably, most of the previous neuroimaging studies investigating action inhibition have employed experimental paradigms in which participants had to inhibit responses to external stimuli (e.g., Aron, Fletcher, Bullmore, Sahakian, \& Robbins, 2003; Konishi, Nakajima, Uchida, Sekihara, $\&$ Miyashita, 1998). Thus, the results of these studies cannot readily be generalized to endogenous decisions to execute or inhibit an intended action. This issue has recently been addressed by an elegant fMRI study (Brass \& Haggard, 2007) using a variant of the temporal judgment task developed by Libet, Gleason, Wright, and Pearl (1983). Participants were asked to make spontaneous keypresses while observing a rotated clock hand, or, in some trials (voluntarily selected by the participants), to cancel the intended response at the last possible moment. The results showed that a specific area of the fronto-median cortex was more strongly activated when participants prepared a keypress but then intentionally canceled it. Albeit speculatively, we find it possible that this brain region could underlie our ability to refrain from doing something, even when we have made a genuine decision to do it. In the next three sections, we will describe how the different types of akratic actions and different psychopathological distur- bances can be categorized according to this three-stage model of decision making.

\section{DYSFUNCTIONAL OPTION GENERATION}

Option generation could be dysfunctional because of the form of the process (the number of options generated) or the content of the process (the nature of the generated options). Here, we focus on the form of the process. An important distinction in this respect is the difference between the hypo- and hyper-generation of options; either can have distinct effects on the following phases of the decision-making process.

\section{Hypogeneration of Options}

Apathy. In the philosophical literature, certain kinds of akrasia are described as cases of accidie - that is, sloth, or just not caring (Dancy, 1993; A. O. Rorty, 1988; Stocker, 1979; Tenenbaum, 2003). The idea is that sometimes people just do not care about translating their general values into concrete options for action. For instance, whereas Bessie has been looking forward to spending her holiday doing all kinds of interesting things, she now just cannot come up with any options for action that she considers worthwhile. By not seeing the possibility that something could be an option for action, one is unable to transform values into action. After all, in such cases, the person usually still has values: If asked what she thinks to be good in life in general, Bessie would probably have some answer. The problem is that in her current situation, these general values do not lead to the formation of corresponding options for action. This is what makes Bessie irrational: She is not forming options for action that correspond with her general values.

Just as option generation has received little attention in decision-making research, akrasia as accidie has not attracted a lot of philosophical attention either. Most philosophical analyses of akrasia focus on problems with translating existing options into action. Such problems could be described in terms of instrumental (ir)rationality. For example, people are irrational in the sense that they do not choose the best means for reaching their goals. This view is often traced back to David Hume, and it is also associated with Weber's concept of Zweckrationalität. According to Hollis (1994), "Zweckrational action is to be understood by reconstructing the calculation of expected utility which went into it: why Jack's choice of apples rather than pears was rational, given his preferences, information and resources" (p. 149). This type of rationality also plays an important role in fields such as neuroeconomics and game theory; we will address it further in the section on option selection dysfunctions.

Much remains to be said about how such options are actually formed. Rational decision making is not only about choosing between options, but also about determining what your genuine options for action are (Frankfurt, 1988; Gibbard, 1990; Hooker \& Streumer, 2004; Raz, 2005). Therefore, it seems worthwhile to focus not only on problems concerning option selection, but also on the 
kinds of irrationalities that point to defects in the process of option generation. Hypogeneration of options is, in the philosophical discussion, usually understood to be a lack of motivation. People who suffer from akrasia as accidie are thought to lack motivational drive or energy (Mele, 1987; Stocker, 1979; Tenenbaum, 2003). However, this is not the only explanation available. As mentioned in the introduction, we define an option as a cognitive-motor program (representing the action as well as its conditions on a cognitive-motor level), which is associated with a certain affective value. Option generation thus seems to involve both cognitive and motivational components. Akrasia as accidie may result from a failure in either component. It may be that one does not generate options because of a failure to attach affective value to a cognitive-motor program; this would be a motivational failure. However, it may also be that one does not generate options because of a failure to form cognitive-motor programs. In common language, one would say that Bessie's failure to generate options is due either to a failure to see any value in possible actions (a motivational failure) or to a failure to come up with possible actions at all (a cognitive failure).

We propose that a decrease in the number of generated options manifests itself as apathy on a phenomenological level - that is, as a quantitative reduction of self-generated and purposeful behavior (Brown \& Pluck, 2000; Levy \& Dubois, 2006; Marin, 1996). If isolated, this type of apathy would result in a lack of options for action, whereas the capacity to decide from among given options or to execute actions remains intact. In the context of this article, we use the term apathy only as a description of psychopathological phenomena, not as a designation of a specific underlying mechanism (see Figure 2). From a psychopathological point of view, the possibility of a specific deficit in option generation is best discussed in conjunction with recent conceptions of apathy, in which different underlying cognitive-affective and neural disturbances have been postulated. Levy and Dubois (2006) have defined a syndrome of cognitive inertia, which is thought to result from impairment in the elaboration of plans of actions and is associated with lesions of the dorsolateral and ventrolateral prefrontal cortex and its subcortical connections. Although these authors see cognitive inertia mainly as a deficit in executive control of the action once a decision has been taken, they conclude that it is related to difficulties in elaborating new patterns of behavior. We would suggest that a key element of this type of apathy is one's inability to generate options for action in real-world environments with few constraints.

So far, hypogeneration of options as a causal mechanism for apathy has not been addressed in lesion studies. However, there is indirect evidence supporting the assumption that a disturbance of option generation contributes to apathy observed in patients with lesions of the dorsolateral and ventrolateral prefrontal cortex. These patients have trouble with ill-structured situations, despite having intact IQ and memory (Goel, Grafman, Tajik, Gana, \& Danto, 1997), and the spontaneous generation of words and more general ideas is reduced; the impairment is larger with lower external constraints (Baldo \& Shimamura, 1998).
We find it interesting that the most severe forms of cognitive inertia are observed not with cortical lesions but with lesions of the head of the caudate nucleus (Bhatia \& Marsden, 1994).

This failure to generate ideas for action in ill-constrained environments was also considered to be characteristic of schizophrenia by Kraepelin (1919). More recently, a renewed interest in the negative symptoms of schizophrenia has led to psychometric research directly addressing apathy as a core negative symptom of the illness (Faerden et al., 2008). However, experimental research has only just begun to elucidate which mechanisms contribute to apathy in patients with schizophrenia and whether they differ from those of patients with neurological disorders (Rao, Spiro, Schretlen, \& Cascella, 2007; Roth et al., 2008). Spence and colleagues have introduced the concept of response space, which they define as the distribution of possible actions in a given situation (Spence \& Parry, 2006). Patients with schizophrenia are thought to have a smaller response space than healthy subjects (i.e., they produce lower variation in their courses of actions). This concept is backed by the findings of studies that required subjects to vary timing and order of responses (Ganesan, Green, Hunter, Wilkinson, \& Spence, 2005). This narrowing of response space corresponds well with an impairment of option generation. However, the empirical evidence comes largely from constrained experimental settings, which raises the question of applicability to real-world situations.

A recent study addressing real-world functioning in patients with schizophrenia has found impairment in the spontaneous generation of solutions, although this was not the main goal of the study (Revheim et al., 2006). Revheim et al. used the Independent Living Scales to address capacity for daily problem solving. This instrument requires subjects to verbalize solutions to real-world problems - for example, "What might you do if your lights and TV went off at the same time?" Moreover, performance on experimental tasks designed to measure responses to such types of real-world problems shows similar impairments, which are strongly associated with negative symptoms and executive functioning in patients with schizophrenia (Semkovska, Stip, Godbout, Paquet, \& Bédard, 2002). Impairment on verbal and other fluency tasks has also been consistently reported and is associated with hypoactivation of left dorsolateral and frontopolar prefrontal cortex (Curtis et al., 2001; Takizawa et al., 2008). Traditionally, creativity has been thought to be increased in patients with schizophrenia (Andreasen, 1987), but recent evidence has found an opposite pattern of decreased creativity in patients with negative symptom schizophrenia (Abraham, Windmann, McKenna, \& Güntürkün, 2007), which is in line with the analysis we propose here.

As already stated, clinical observation in patients with frontal lobe lesions and schizophrenia suggests a deficit in generating options for action. However, at present, only indirect evidence for disturbances on related tasks is available. Therefore, the next step would be the development and application of experimental paradigms, which would necessarily build on the research in creativity and complex problem solving. 


\section{Hypergeneration of Options}

Loss of goal directedness. At first glance, hypergeneration of options does not seem to constitute a problem. Indeed, an increase in the number of generated options can have beneficial consequences, such as an increase in creative drive (Flaherty, 2005; Jamison, 1995). However, depending on individual and situational circumstances, only a limited number of options can be included in decision making without disturbing the goal directedness of behavior (Klein \& Wolf, 1998). Thus, a person can generate so many options that it becomes almost impossible to select or act on any one of them.

The clinical effects of hypergeneration of options are likely to depend on its interaction with later stages of decision making. If more options are turned into actions, one will observe an increase in activity, but that activity will lack goal directedness. This phenomenon is commonly observed in manic syndromes, which occur in the context of bipolar disorder, as well as in persons with focal brain lesions and intoxications (American Psychiatric Association, 1994). Hyperactivity has also been proposed as the key symptom of hypomania, a mild form of mania bordering on phenomena observed in nonclinical populations (Benazzi, 2007). Another possibility is that the mere abundance of options "overloads" the later stages of decision making. It could disproportionately extend the option selection phase or even disrupt the decision making process at this phase. Alternatively, a large number of options could be selected but not be executed. In fact, extreme cases of mania are often accompanied by catatonic features with a reduction of spontaneous behavior (Bräunig, Krüger, \& Shugar, 1998).

The possibility of suffering from akrasia as a result of generating too many options is rarely discussed in the philosophical debate. However, it may very well be that some of the classic philosophical examples could be explained in terms of a hypergeneration of options that subsequently leads to problems in option selection. It might apply to the example of Bessie we discussed in the introduction: Maybe Bessie has generated so many options for spending her holiday that the sheer number of options prevents her from doing anything in a goal-directed way. People in the normal population who often experience such troubles might suffer from mild, subclinical forms of hypomania.

\section{DYSFUNCTIONAL OPTION SELECTION}

Problems may also occur in the stage of weighing options and making a decision. Contrary to the dysfunctions described in the previous section, here the agent certainly sees enough (and not too many) options for actions. However, he or she is still unable to reach a good decision about what to do here and now. Although there is no specific philosophical term for this kind of akrasia, we could refer to it as decisional akrasia: One knows what he or she values, but makes either the wrong decision or no decision at all.

To return to the example of Bessie, let us say she realizes that she wants to use her holiday time to read some novels and do some serious work in the garden. Her op- tion generation skills are in full function. But now, we can imagine Bessie having problems with option selection: Maybe she still cannot decide what to do right now; maybe she decides to go upstairs and lie in bed anyway. In that case, Bessie's action is irrational, because her decision about what to do somehow does not correspond with the attached value of the options she has generated. In the philosophical debate, this type of akrasia is usually explained as a divergence between evaluation and motivation (Davidson, 2001; Mele, 1987). The idea is that when people make irrational decisions, it is the result of a gap between what one determines to be most desirable and what one actually desires most. To quote Stroud and Tappolet (2003, p. 18), "It is generally acknowledged that ... practical irrationality ... involves a coming apart of the motivational force of the agent's wants from his assessment of the objects of those wants." On the one hand, people evaluate their wants or desires: They assess how worthwhile and important they consider their desires to be-how desirable they judge their desires to be. On the other hand, their decision about what they ultimately want to do is made under the influence of motivational factors that operate outside the realm of deliberation (A. O. Rorty, 1985). Another explanation is that one makes the wrong decision because one judges certain options to be more or less feasible than they actually are. As mentioned before, this would be an example of instrumental irrationality, of not choosing the best means for reaching one's goals (Hollis, 1994). Thus, decisional akrasia may also be caused by faulty reasoning.

\section{Making the Wrong Decision}

Impulsivity and compulsivity. In psychiatry, a wide variety of disorders have been related to dysfunctional option selection. This also relates to the fact that a broad range of parameters, such as expected value of options, associated uncertainty, and the timing of the expected outcome, enter into option selection. Here we focus on the phenomena of impulsivity and compulsivity, which most closely relate to akrasia. As stated above, in the philosophical literature, akrasia is often contrasted with symptoms such as addiction and compulsion. Addiction and compulsion are then presented as two different manifestations of the same thing - namely, unfree actions or actions caused by irresistible desires (Mele, 2002; Searle, 2001; Walsh, 1975). This philosophical understanding of compulsion and addiction differs greatly from the way these phenomena are understood in psychiatry and clinical psychology. An important difference is that in psychiatry, the concept of freedom does not play a dominant role in demarcating diagnostic categories; psychiatrists do not generally assume that psychopathological behavior is unfree. Furthermore, psychiatry considers addiction and impulsivity to be closely related phenomena, whereas compulsions and compulsiveness fall into a different category.

In the context of parameters affecting option selection, impulsive decision making has been proposed to involve an underestimation of risk and/or a strong preference of immediate over future gains (Wittmann \& Paulus, 2008). The experimental findings regarding compulsive decision 
making are less clear-cut, as will be discussed below. On a phenomenological level, compulsive actions are often performed in order to avoid an event in the future. Here an inappropriately high risk is attributed to this event, and future consequences of any action are overvalued in relation to short-term consequences. It is important to note that both patients suffering from compulsivity and those suffering from impulsivity are capable of creating alternative options; it is the appropriate assessment of options and their selection for action that is dysfunctional.

Impulsivity is considered a heterogeneous construct with several putative mechanisms that contribute to the clinical phenomenon (Evenden, 1999; Moeller, Barratt, Dougherty, Schmitz, \& Swann, 2001). A dysfunction on the level of option selection has been termed choice impulsivity, in contrast with motor impulsivity, which occurs during later stages of decision-making. Two main mechanisms have been thought to contribute to choice impulsivity (Cardinal, 2006). One is an inappropriate assessment of risk, which has been consistently associated with impulsivity in gambling tasks (Best, Williams, \& Coccaro, 2002). Since we approach akrasia as differing only in a gradual sense from psychopathological phenomena, it is important to note that subclinical forms of impulsivity are also associated with inappropriate risk assessment (Franken, van Strien, Nijs, \& Muris, 2008; Zermatten, Van der Linden, d'Acremont, Jermann, \& Bechara, 2005). On a neural level, the orbitofrontal cortex has been found to code for uncertainty in healthy volunteers with interindividual differences in risk seeking (Tobler et al., 2007). Classically, lesions of the orbitofrontal cortex have led to rather extreme cases of impulsive action (see, e.g., the case of Phineas Gage, as described in Macmillan, 2000). These lesion studies have formed the basis for Damasio's somatic marker hypothesis, which emphasizes the role of emotional information in decision making under risk (Damasio, 1994). A second mechanism currently discussed in association with choice impulsivity is a decreased valuation of future rewards (Wittmann \& Paulus, 2008). This pattern has consistently been observed when patients with impaired impulse control perform so-called delay discounting tasks (Reynolds, 2006).

What follows from this is that cases of decisional akrasia show similarities to symptoms associated with impulsivity. Such an approach is outlined by Ainslie (2001, 2006), who analyzes this type of akrasia in terms of hyperbolic discounting, one of the proposed mathematical functions by which people discount future gains. As outlined above, people with impulse control problems characteristically have difficulty letting go of small but immediate rewards in order to avoid large disadvantages in the longer term. This connects the debate about akrasia with psychological insights about intertemporal decision making. Someone who, while trying to lose weight, succumbs upon smelling a gorgeous pizza is probably experiencing problems with impulse control. Decisional akrasia involving the use of alcohol or illicit substances shows the same pattern. Opinions differ about whether dependence is primarily an impulse control disorder, but there is evidence for common mechanisms, as well as a high comorbidity of impulse control disorders and drug dependence (Bechara, 2005; Lejoyeux, Feuché, Loi, Solomon, \& Adès, 1999).

Compulsions or compulsivity have traditionally been thought to reflect the opposite of impulsivity; they are associated with risk avoidance and a decreased tolerance of uncertainty (Obsessive Compulsive Cognitions Working Group, 1997). This view has been challenged on the grounds of heterogeneous results in studies that psychometrically addressed impulsivity and compulsivity. Moreover, serotonin depletion appears to be a common neurobiological correlate of both impulsivity and compulsivity (Grant \& Potenza, 2006). The performance of subjects with obsessive-compulsive disorder (OCD) on gambling tasks has also been a matter of controversy (Cavedini, Gorini, \& Bellodi, 2006; Chamberlain et al., 2007; Lawrence et al., 2006). Recent evidence suggests that decision-making performance is differentially associated with specific OCD symptom clusters (Lawrence et al., 2006). The category most closely corresponding to the classical view would be the checking symptom category. Here, the patient performs certain actions (checks) in order to avoid some catastrophic event in the future. Indeed, this symptom dimension correlates negatively with impulsivity and does not show increased risk taking in gambling tasks (Lawrence et al., 2006; Li \& Chen, 2007). We would hypothesize that an inappropriately high valuation of future consequences of action is associated mainly with the checking symptom dimension, but appropriate experimental tasks on intertemporal decision making have yet to be applied to the study of compulsive symptoms.

Compulsivity may play a role in some cases of decisional akrasia, in the sense that compulsive tendencies can prevent people from selecting the best option. This happens in two ways. In one instance, the inappropriate risk assessment associated with compulsivity (Obsessive Compulsive Cognitions Working Group, 1997) distorts the process of option selection and may result in a decision that does not contribute optimally to goal achievement. Similarly, such inappropriate risk assessment can severely prolong the process of decision making, as people are afraid to make the wrong decision. As such, subclinical compulsive tendencies might manifest themselves as indecisiveness in daily decision-making situations. Let us apply this to the Bessie example: Maybe Bessie is unable to make a decision concerning how to spend her holiday because she worries too much about the future consequences of her choices.

\section{Making No Decision}

Ambivalence. At this point, it seems important to mention the symptom of ambivalence classically associated with schizophrenia (Bleuler, 1911). Bleuler defined ambivalence as a tendency to simultaneously experience divergent emotions relating to situations, objects, or people, which in turn leads to an impairment of voluntary action. In the modern schizophrenia literature, ambivalence was conceptualized as a core symptom of schizotypy - that is, the latent personality organization that provides the liability for the development of the illness (Meehl, 1962). In recent psychopathologic and psychometric research, the term is used 
in a very broad sense and has not focused on ambivalence regarding decisions (Kwapil, Raulin, \& Midthun, 2000). Therefore, the available rating scales are of limited help for use in the context of a psychopathology of action. In the context of our stage model of decision making, we think ambivalence is best conceptualized as a true reduction in the quantitative capacity to select options (i.e., the subject cannot decide, even when two clear options are given). This narrowing of the term could provide a basis for a cognitive neuropsychiatric investigation of ambivalence.

Ambivalence may be related to protracted decision making or even to the failure to make any decision at all, because every time an option for a particular course of action is generated, this option elicits both positive and negative emotions. From the perspective of social psychology, ambivalence has been defined as the coexistence of positive and negative evaluations of an attitude object (Armitage \& Conner, 2000). In this line of research, ambivalent attitudes are generally conceptualized as rather weak attitudes, as they are less predictive of future behavior, less stable, and more susceptible to persuasion (Armitage \& Conner, 2000). Notably, healthy individuals have been found to spontaneously engage in biased information processing to resolve instances of ambivalence-for example, by selective elaboration of one-sided information (Nordgren, van Harreveld, \& van der Pligt, 2006). Therefore, it is tempting to speculate that schizophrenic patients may suffer from ambivalence because they are not able to spontaneously resolve evaluative conflict. Future studies should investigate the relationship between ambivalence and biased information processing in both healthy individuals and patients suffering from schizophrenia.

Interestingly, there is now emerging evidence that a network including the orbitofrontal lobe may be related to ambivalence. Thus, one pronounced deficit demonstrated by patients with lesions of the orbitofrontal cortex is a large increase in deliberation times associated with their decisions (Rogers et al., 1999). This finding reflects the clinical observation that such patients take protracted times to make decisions in everyday life, thereby supporting the notion that damage to the orbitofrontal cortex is associated with deficits in decision making when there is limited contextual information to help to identify the optimal response (Rahman, Sahakian, Cardinal, Rogers, \& Robbins, 2001). Thus, disrupted access to somatic markers could lead not only to inappropriately risky decisions, but also to a delay in reaching or an inability to reach a decision in situations with few constraints (Damasio, 1994).

Thus, although there are viable starting points for research on ambivalence in the psychometric and neuropsychological literature, most of the evidence regarding its role in a psychopathology of action is indirect. Likewise, in philosophical discussions on decisional akrasia, ambivalence has not received a lot of attention. ${ }^{1}$ Nevertheless, it is plausible that many examples of akrasia involve this type of ambivalence. In many cases, the problem may be that people just cannot make up their minds, even when the different options for action are clear to them. Ambivalence as one core mechanism for option selection dysfunction will thus certainly require research on the phenomenological as well as the cognitive neuropsychiatric level.

\section{DYSFUNCTIONAL ACTION INITIATION}

Certain cases of akrasia seem to be the result of dysfunctional action initiation. Many cases have been described as follows: There is an intention to perform a certain action (based on a decision), but that action is not performed. Let us return to Bessie once more. Now she has decided to go to work in the garden. She has selected the option of reorganizing the garden during her holiday. Bessie has thus generated options and selected one of them. She has decided which of her goals to pursue right now. However, Bessie still does not act on her decision. Hours later, she is still lingering in front of the television. This kind of irrationality is about not acting on the decision you have made. This type of akrasia is usually called last-ditch akrasia - acting against one's decision at the very last moment (Mele, 1987). This is different from the kind of akrasia associated with option generation dysfunction, in which the agent does not have any options for action or has too many options, and from the kind of akrasia associated with option selection, in which the agent makes either the wrong decision or no decision at all. Philosophical models of last-ditch akrasia sometimes make use of the concept of volitional control; in order to translate one's decision into action, one needs to exercise volitional control (Stroud \& Tappolet, 2003). The lack of volitional control can manifest itself either in a different kind of apathy (where one is unable to exercise volitional power and thus does not act on the decision) or in inappropriate behavior (doing things that are not what one decided to do). However, last-ditch akrasia is often explained in the same way as decisional akrasia, by referring to a gap between evaluation and motivation (Mele, 1987). On such a model, motivation is needed not only to make the correct decision, but also to translate one's decision into action. Such a view contrasts with Heckhausen's (1991; Heckhausen \& Gollwitzer, 1987) distinction between motivation and volition, in which the predecisional processes are considered motivational, and the postdecisional processes volitional.

\section{Impaired Action Initiation}

Motor inertia. We propose that apathy on the phenomenological level may also be caused by an impairment of action initiation. In contrast to the cognitive inertia relating to the option generation stage, we find here a form of motor inertia (Levy \& Dubois, 2006; Marin, 1996). The subject is well aware of options for action and is even able to select one, but is nevertheless incapable of initiating the action in time. This type of apathy can be observed in disorders of dorsomedial frontal prefrontal and anterior cingulate cortex areas subserving the planning and execution of motor actions (Cohen et al., 1999). In classical formulations of fronto-subcortical circuits, disturbances in the anterior cingulate-nucleus accumbens circuit have also been associated with apathy, but with a more general functional role as a driving force for motivated behavior - a role thus not restricted to action initia- 
tion (Mega \& Cummings, 1994). To reconcile these views, it has to be kept in mind that in our framework, motor inertia does not relate solely to simple motor acts, but also to the complex motor plans necessary for executing a selected option. The fronto-subcortical circuit approach explains why these disturbances can arise due to a direct lesion of dorsomedial frontal areas and why they are also common in basal ganglia diseases, such as Parkinson's disease (Kropotov \& Etlinger, 1999). Impaired spontaneous action initiation has also been observed in patients with schizophrenia, although the underlying mechanisms have been subject to debate (Frith, 1992; Reuter, Jäger, Bottlender, \& Kathmann, 2007).

\section{Facilitated Action Initiation}

Hyperactivity and motor impulsivity. In contrast to a reduction in action initiation, an inappropriate facilitation or lack of inhibition can result in hyperactivity, which can occur on different levels of behavior. The most common example can probably be observed in attention deficit hyperactivity disorder, which in a mild form also frequently occurs in the normal population (Spencer, Biederman, \& Mick, 2007). Hyperactivity as the result of a lack of motor inhibition in the normal population may also be a manifestation of last-ditch akrasia, when hyperactivity prevents the agent from attaining his or her goals and acting on his or her decisions. This would allow for more fine-grained explanations of last-ditch akrasia in terms of volitional control: Volitional control requires both volitional power and inhibitory control. However, last-ditch akrasia as a result of hyperactivity is probably less common than lastditch akrasia as a result of impaired action initiation.

An impairment of inhibitory control has also been thought to be related to impulsivity (Chamberlain \& Sahakian, 2007; Moeller et al., 2001). In contrast to choice impulsivity related to option selection, we would hypothesize motor impulsivity to be related to action initiation (Evenden, 1999). Despite abundant evidence showing impaired inhibition in disorders with loss of impulse control, some inconsistencies remain (Chamberlain \& Sahakian, 2007; Logan et al., 1997; Rentrop et al., 2007). To address this issue, one would have to separate the different types on a phenomenological level, which has now been done in psychometric studies. In a second step, this differentiated psychopathological approach would have to be linked with experimental paradigms examining the processes of option selection and action inhibition.

In our attempt to categorize psychopathological symptoms in a decision-making framework, the ideal case would be that a symptom maps specifically onto one of these stages. However, a clinical symptom can arise from separate stages of decision making, as has been shown for the case of impulsivity. Similarly, the apathetic patient could fail to generate options, fail to decide between options, or fail to initiate actions. Although symptoms resulting from these disturbances may look similar at first glance, we would suggest that a more detailed exploration of the phenomenology of the symptom would allow for differentiation at the clinical and psychometric levels. Steps toward this differentiation have already been taken - for example, in factor analytic studies of the Apathy Evaluation Scale (Marin, 1996). Ultimately, clinical, psychometric, and experimental approaches should be combined to develop a differentiated psychopathology of action (see Tables 1 and 2).

\section{CONCLUSION: BENEFITS AND LIMITS OF AN INTEGRATIVE APPROACH}

When one accepts the application of our or a comparable framework to the study of akrasia and psychopathology, there are several fruitful avenues for further research. First, our combined philosophical and psychopathological analysis has identified gaps in philosophical, psychologi$\mathrm{cal}$, and neuroscientific approaches to voluntary action and decision making. The most prominent example is option generation, which has rarely been studied in the context of decision making. Second, our framework demands a systematic application of tasks that address each stage of decision making in conjunction with appropriate psychopathological rating scales in order to link these levels of explanation. Finally, it opens up possibilities for a new approach to questions regarding the irrational actions for which we can hold people responsible. If akratic phenomena are in important respects similar to psychopathological phenomena, this could change our view on responsibility.

\section{Philosophical Perspective}

The inventory of psychopathological symptoms related to decision making offers an interesting view on the relationship between akrasia and mental illness. Most agents who display akratic behavior do not fulfill the criteria for any psychiatric symptom, and hardly any of them will fulfill the criteria for a full-blown psychiatric disorder, mainly because akratic behavior does not usually severely interfere with the agent's daily functioning. Still, some akratic agents might actually fulfill such psychopathological criteria. Certain kinds of akrasia could be understood as mild forms of psychopathology. This suggests that the distinction between psychopathology and daily problems in decision making in the normal population should be understood to be on a gradual scale of difference. This also corresponds to a growing tendency in current psychiatry to understand symptoms and disorders as dimensions, rather than as distinct categories (Nathan \& Langenbucher, 1999; Widiger \& Sankis, 2000). The advantage of such an approach is that contrary to the classical philosophical approach that tries to incorporate akrasia into a model of normal action, this view can account for our experience of akratic behavior as anomalous and dysfunctional behavior (Campbell, 2000).

It is important to emphasize that despite the interesting overlap between philosophical and psychiatric points of view, the aims and starting points in philosophy are different from those in psychiatry. This implies that neuropsychiatric insights will not be relevant for all aspects of the philosophical debate on akrasia. In part, the philosophical problem of akrasia is a problem that requires a philosophical (i.e., conceptual) solution. Philosophical analyses of 
Table 1

Psychopathological Symptoms Associated With Each Stage of the Model, As Well As Examples of Psychopathological Rating Scales That Address Specific Phenomena Either As a Summary Score or As a Factor Score

\begin{tabular}{|c|c|c|}
\hline Stage & Psychopathological Symptom & Rating Scale \\
\hline \multirow[t]{2}{*}{ Option generation } & (Cognitive) apathy & $\begin{array}{l}\text { Scale for the Assessment of Negative Symptoms }{ }^{\mathrm{b}} \text { (Andreasen, 1983) } \\
\text { Apathy Evaluation Scale }{ }^{\mathrm{b}} \text { (Marin, Biedrzycki, \& Firinciogullari, 1991) } \\
\text { Lille Apathy Rating Scale }{ }^{\mathrm{b}} \text { (Sockeel et al., 2006) }\end{array}$ \\
\hline & Loss of goal directedness/hypomania & Mood Disorder Questionnaireb (Benazzi \& Akiskal, 2003) \\
\hline \multirow[t]{3}{*}{ Option selection } & Impulsivity & $\begin{array}{l}\text { I7 Questionnaire }{ }^{c} \text { (Eysenck \& Eysenck, 1985) } \\
\text { Barratt Impulsiveness Scale (Patton, Stanford, \& Barratt, 1995) }\end{array}$ \\
\hline & Compulsivity & 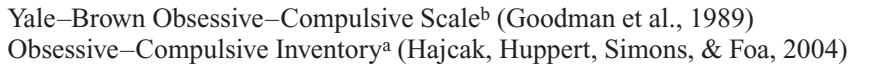 \\
\hline & Ambivalence & Intense Ambivalence Scale (Kwapil, Raulin, \& Midthun, 2000) \\
\hline \multirow[t]{2}{*}{ Action initiation } & (Motor) apathy & $\begin{array}{l}\text { Motor Agitation and Retardation Scaleb (Sobin, Mayer, \& Endicott, 1998) } \\
\text { Lille Apathy Rating Scaleb (Sockeel et al., 2006) }\end{array}$ \\
\hline & Hyperactivity/motor impulsivity & $\begin{array}{l}\text { College ADHD Response Evaluationc (Glutting, Youngstrom, \& Watkins, 2005) } \\
\text { Barratt Impulsiveness Scalea (Patton et al., 1995) } \\
\text { Motor Agitation and Retardation Scale }{ }^{\mathrm{b}} \text { (Sobin et al., 1998) }\end{array}$ \\
\hline
\end{tabular}

anstruments used in clinical as well as nonclinical populations. ${ }^{\mathrm{b}}$ Clinical populations only. ${ }^{\mathrm{c}}$ Nonclinical populations only.

Iable 2

Component Processes Associated With Each Stage, As Well As Possible Approaches to Neuropsychological Examination of These Processes, Through Either Behavioral Testing or Functional Imaging

\begin{tabular}{|c|c|c|}
\hline Stage & Component Process & Neuropsychological Test \\
\hline \multirow[t]{2}{*}{ Option generation ${ }^{\mathrm{a}}$} & Retrieval of options & $\begin{array}{l}\text { Fluency tasks (Lezak, Howieson, Loring, Hannay, \& Fischer, 2004) } \\
\text { Time and order variation tasks (Spence \& Parry, 2006) }\end{array}$ \\
\hline & Creating new options & Alternative Uses Test (Guilford, Christensen, Merrifield, \& Wilson, 1978) \\
\hline \multirow[t]{2}{*}{ Option selection } & Intertemporal decision making & Delay discounting tasks (Ainslie, 2001; McClure, Laibson, Loewenstein, \& Cohen, 2004) \\
\hline & Risk and uncertainty coding & $\begin{array}{l}\text { Iowa Gambling Task (Bechara, Damasio, Damasio, \& Anderson, 1994) } \\
\text { Monetary incentive task with variation of probabilities (Tobler, O’Doherty, Dolan, } \\
\text { \& Schultz, 2007) }\end{array}$ \\
\hline \multirow[t]{2}{*}{ Action initiation } & Initiation & $\begin{array}{l}\text { Self-paced motor acts (Cunnington, Windischberger, Deecke, \& Moser, 2002) } \\
\text { Saccade initiation (Reuter, Jäger, Bottlender, \& Kathmann, 2007) }\end{array}$ \\
\hline & Inhibition & $\begin{array}{l}\text { Intentional inhibition (Brass \& Haggard, 2007) } \\
\text { Go/no-go tasks (Kaiser et al., 2008) }\end{array}$ \\
\hline
\end{tabular}

${ }^{a}$ Currently, there is no task that assesses option generation in experimental situations approximating real-world situations.

decision making and its dysfunctions are ultimately attempts to clarify concepts such as responsibility, freedom, and agency. Such concepts are in turn employed to search for justifications of our social and moral practices. One reason why philosophers want to distinguish akrasia from psychopathological phenomena is that they are interested in determining the failures for which we should hold ourselves and others responsible and those for which we should not (Kennett \& Smith, 1994; Walsh, 1975). However, of course, determining criteria for responsibility is certainly not only a conceptual issue, but also a political, legal, psychological, and social issue. In this article, we have emphasized that the philosophical discussion about akrasia is also a reflection on certain behavioral phenomena as they occur in our daily lives. Insofar as we are interested in understanding these phenomena, insights from psychology and psychiatry may prove helpful.

\section{Psychopathological Perspective}

From the perspective of psychopathology, the study of different types of akrasia can serve as a heuristic for a psychopathology of action, which can be contrasted with the psychopathology of perception, thought, and affect. Generally, this consists of either an increase or a decrease in activity (e.g., apathy) or, alternatively, in the occurrence of abnormal action-related phenomena (e.g., compulsions). Much current psychopathological research consists of an accumulation of a large number of empirical details and often completely lacks a theoretical framework. One often finds overlapping findings when neurocognitive mechanisms of two or more disorders are compared. For example, deficits in response inhibition have been described in schizophrenia, depression, borderline personality disorder, ADHD, mania, and other disorders (Kaiser et al., 2008). However, it is very difficult to clarify the role for this deficit in each disorder. A philosophically informed theoretical framework could be of help in linking deficits in decision making with symptoms rather than disorders. This could also prove valuable in dimensional approaches, which are likely to play a larger role in the construction of the DSM-V.

This kind of research program would link the level of psychopathology in a specific domain (e.g., ambivalence) with the level of dysfunction in the associated decision- 
making stage (e.g., option selection). Ideally, this relationship would be exclusive - that is, the respective phenomenon would occur only in conjunction with deficits in one stage and not in others. Conversly, deficits in a specific stage should lead only to the phenomena postulated in our model. The current state of knowledge already allows for an assessment of most parts of the model. Psychopathological phenomena need to be assessed with appropriate rating scales (see Table 1). A problem in this field arises when related phenomena need to be clearly differentiated (e.g., cognitive and motor apathy, choice and motor impulsivity), but this problem is now the subject of factoranalytic studies (Patton, Stanford, \& Barratt, 1995; Sockeel et al., 2006). Deficits in the stages of decision making have to be addressed with appropriate neuropsychological tests (see Table 2). We have pointed out important gaps in the tests available, focusing on option generation. We are currently at work on the development of a test for assessing option generation as it is defined in our model.

\section{Limitations and Conclusions}

In the present article, we have tried to provide an interesting interdisciplinary outlook on those daily irrationalities usually attributed to weakness of will. Also, we have tried to offer a model that provides promising theoretical distinctions and testable empirical hypotheses amenable for future research. However, we acknowledge that our model is still very general, and that we will have to prove its usefulness in concrete empirical studies. In addition, our categorization of dysfunctional decision making in three different stages is, of course, not exhaustive: We do not claim that all problems in decision making for action can be described in these terms. The model could be expanded by adding the previously mentioned later stages, action monitoring and outcome evaluation. Also, there are other possible dimensions on which decision-making problems could be categorized, such as the domain of decisions that are dysfunctional, or the phenomenological characteristics of the dysfunctions. Nevertheless, we think our proposal can enrich the study of action and decision making by offering a model that (1) identifies relevant similarities and differences among several dysfunctions, (2) offers concrete possibilities for empirical research on underlying processes, and (3) connects insights from psychiatry with insights in weakness of will as discussed in philosophy and psychology.

\section{AUTHOR NOTE}

The collaboration among the authors was made possible by a grant from the Volkswagen Foundation, and the article was written as part of the "European Platform for Life Sciences, Mind Sciences, and the Humanities" initiative of the Volkswagen Foundation. The authors thank Gerben Meynen for his valuable comments on an earlier draft of this article. Correspondence concerning this article should be addressed to A. Kalis, Ethics Institute, Department of Philosophy, Utrecht University, Heidelberglaan 8, 3584CS Utrecht, The Netherlands (e-mail: a.kalis@ uu.nl).

\section{REFERENCES}

Abraham, A., Windmann, S., McKenna, P., \& Güntürkün, O. (2007). Creative thinking in schizophrenia: The role of executive dysfunction and symptom severity. Cognitive Neuropsychiatry, 12, 235-258.

Ainslie, G. (2001). Breakdown of will. Cambridge: Cambridge University Press.

AinsLie, G. (2006). A selectionist model of the ego: Implications for self-control. In N. Sebanz \& W. Prinz (Eds.), Disorders of volition (pp. 119-150). Cambridge, MA: MIT Press.

Ainslie, G., \& Monterosso, J. (2004). A marketplace in the brain? Science, 306, 421-423.

AMERICAN PSYCHIATRIC Association (1994). Diagnostic and statistical manual of mental disorders (4th ed.). Washington, DC: Author.

ANDREASEN, N. C. (1983). Scale for the Assessment of Negative Symptoms (SANS). Iowa City, IA: University of Iowa.

Andreasen, N. C. (1987). Creativity and mental illness: Prevalence rates in writers and their first degree relatives. American Journal of Psychiatry, 144, 1288-1292.

Aristotle (2002). Nicomachean ethics (S. Broadie, Ed., \& C. Rowe, Trans.). Oxford: Oxford University Press.

Armitage, C. J., \& Conner, M. (2000). Attitudinal ambivalence: A test of three key hypotheses. Personality \& Social Psychology Bulletin, 26, 1421-1432.

Aron, A. R., Fletcher, P. C., Bullmore, E. T., Sahakian, B. J., \& Robbins, T. W. (2003). Stop-signal inhibition disrupted by damage to right inferior frontal gyrus in humans. Nature Neuroscience, $\mathbf{6}$, 115-116.

Aron, A. R., Robbins, T. W., \& Poldrack, R. A. (2004). Inhibition and the right inferior frontal cortex. Trends in Cognitive Sciences, 8 , 170-177.

ARPaly, N. (2000). On acting rationally against one's best judgment. Ethics, 110, 488-513.

BALDO, J. V., \& ShimAMURA, A. P. (1998). Letter and category fluency in patients with frontal lobe lesions. Neuropsychology, 12, 259-267.

BECHARA, A. (2005). Decision-making, impulse control and loss of willpower to resist drugs: A neurocognitive perspective. Nature Neuroscience, 8, 1458-1463.

Bechara, A., Damasio, A. R., Damasio, H., \& Anderson, S. W. (1994). Insensitivity to future consequences following damage to human prefrontal cortex. Cognition, 50, 7-15.

Bechtereva, N. P., KorotKov, A. D., Pakhomov, S. V., Roudas, M. S., Starchenko, M. G., \& Medvedev, S. V. (2004). PET study of brain maintenance of verbal creative activity. International Journal of Psychophysiology, 53, 11-20.

BenAZZI, F. (2007). Testing new diagnostic criteria for hypomania. Annals of Clinical Psychiatry, 19, 99-104.

BenaZZI, F., \& AKISKAL, H. S. (2003). The dual factor structure of selfrated MDQ hypomania: Energized-activity versus irritable-thought racing. Journal of Affective Disorders, 73, 59-64.

Best, M., Williams, J. M., \& Coccaro, E. F. (2002). Evidence for a dysfunctional prefrontal circuit in patients with an impulsive aggressive disorder. Proceedings of the National Academy of Sciences, 99, 8448-8453.

Bhatia, K. P., \& Marsden, C. D. (1994). The behavioural and motor consequences of focal lesions of the basal ganglia in man. Brain, 117, 859-876.

Bleuler, E. (1911). Dementia praecox oder die Gruppe der Schizophrenien [Dementia praecox or the group of schizophrenias]. Leipzig: Deuticke.

Brass, M., \& Haggard, P. (2007). To do or not to do: The neural signature of self-control. Journal of Neuroscience, 27, 9141-9145.

BräUnig, P., Krüger, S., \& ShUgar, G. (1998). Prevalence and clinical significance of catatonic symptoms in mania. Comprehensive Psychiatry, 39, 35-46.

Brown, R. G., \& Pluck, G. (2000). Negative symptoms: The pathology of motivation and goal-directed behaviour. Trends in Neurosciences, 23, 412-417.

CAmpbell, P. G. (2000). Diagnosing agency. Philosophy, Psychiatry, \& Psychology, 7, 107-119.

CARDinal, R. N. (2006). Neural systems implicated in delayed and probabilistic reinforcement. Neural Networks, 19, 1277-1301.

Cavedini, P., Gorini, A., \& Bellodi, L. (2006). Understanding obsessive-compulsive disorder: Focus on decision making. Neuropsychology Review, 16, 3-15.

Chamberlain, S. R., Fineberg, N. A., Menzies, L. A., Black- 
well, A. D., Bullmore, E. T., Robbins, T. W., \& Sahakian, B. J. (2007). Impaired cognitive flexibility and motor inhibition in unaffected first-degree relatives of patients with obsessive-compulsive disorder. American Journal of Psychiatry, 164, 335-338.

Chamberlain, S. R., \& Sahakian, B. J. (2007). The neuropsychiatry of impulsivity. Current Opinion in Psychiatry, 20, 255-261.

Chávez-Eakle, R. A., Graff-Guerrero, A., García-Reyna, J.-C., VAugier, V., \& CruZ-Fuentes, C. (2007). Cerebral blood flow associated with creative performance: A comparative study. NeuroImage, 38, 519-528.

Christoff, K., \& Gabrieli, J. D. E. (2000). The frontopolar cortex and human cognition: Evidence for a rostrocaudal hierarchical organization within the human prefrontal cortex. Psychobiology, 28, 168-186.

Cohen, R. A., Kaplan, R. F., Zuffante, P., Moser, D. J., JenKINS, M. A., SAlloway, S., \& Wilkinson, H. (1999). Alteration of intention and self-initiated action associated with bilateral anterior cingulotomy. Journal of Neuropsychiatry \& Clinical Neurosciences, 11, 444-453.

Costafreda, S. G., Fu, C. H. Y., Lee, L., Everitt, B., Brammer, M. J., \& DAVID, A. S. (2006). A systematic review and quantitative appraisal of fMRI studies of verbal fluency: Role of the left inferior frontal gyrus. Human Brain Mapping, 27, 799-810.

Cunnington, R., Windischberger, C., Deecke, L., \& Moser, E. (2002). The preparation and execution of self-initiated and externallytriggered movement: A study of event-related fMRI. Neurolmage, 15, 373-385.

Curtis, V. A., Dixon, T. A., Morris, R. G., Bullmore, E. T., BramMer, M. J., Williams, S. C. R., ET AL. (2001). Differential frontal activation in schizophrenia and bipolar illness during verbal fluency. Journal of Affective Disorders, 66, 111-121.

Damasio, A. R. (1994). Descartes' error: Emotion, reason, and the human brain. New York: Avon.

DANCY, J. (1993). Moral reasons. Oxford: Wiley-Blackwell.

DAvidson, D. (2001). How is weakness of the will possible? In D. Davidson (Ed.), Essays on actions and events (2nd ed., pp. 21-42). Oxford: Oxford University Press, Clarendon Press. (Original work published 1969)

Dietrich, A. (2004). The cognitive neuroscience of creativity. Psychonomic Bulletin \& Review, 11, 1011-1026.

ERnst, M., \& PAUlus, M. P. (2005). Neurobiology of decision-making: A selective review from a neurocognitive and clinical perspective. Biological Psychiatry, 58, 597-604.

Evenden, J. L. (1999). Varieties of impulsivity. Psychopharmacology, 146, 348-361.

Eysenck, H. J., \& EysencK, M. W. (1985). Personality and individual differences: A natural science approach. New York: Plenum.

Faerden, A., Nesvi̊g, R., Barrett, E. A., Agartz, I., Finset, A., FRIIS, S., ET AL. (2008). Assessing apathy: The use of the Apathy Evaluation Scale in first episode psychosis. European Psychiatry, 23, 33-39.

Fink, A., Benedek, M., Grabner, R. H., Staudt, B., \& Neubauer, A. C. (2007). Creativity meets neuroscience: Experimental tasks for the neuroscientific study of creative thinking. Methods, 42, 68-76.

Flaherty, A. W. (2005). Frontotemporal and dopaminergic control of idea generation and creative drive. Journal of Comparative Neurology, 493, 147-153.

Franken, I. H. A., van Strien, J. W., Nius, I., \& Muris, P. (2008). Impulsivity is associated with behavioral decision-making deficits. Psychiatry Research, 158, 155-163.

Frankfurt, H. G. (1988). The importance of what we care about: Philisophical essays. Cambridge: Cambridge University Press.

Fried, I., Katz, A., McCarthy, G., Sass, K. J., Williamson, P., SpenCER, S. S., \& SPENCER, D. D. (1991). Functional organization of human supplementary motor cortex studied by electrical stimulation. Journal of Neuroscience, 11, 3656-3666.

FRITH, C. D. (1992). The cognitive neuropsychology of schizophrenia. Hove, U.K.: Erlbaum.

Ganesan, V., Green, R. D., Hunter, M. D., Wilkinson, I. D., \& SPENCE, S. A. (2005). Expanding the response space in schizophrenia: The relevance of left prefrontal cortex. Neurolmage, 25, 952-957.

GiBBARD, A. (1990). Wise choices, apt feelings: A theory of normative judgment. Oxford: Clarendon Press.

GLutting, J. J., Youngstrom, E. A., \& Watkins, M. W. (2005). ADHD and college students: Exploratory and confirmatory factor structures with student and parent data. Psychological Assessment, 17, 44-55.

Goel, V., Grafman, J., TaJik, J., Gana, S., \& Danto, D. (1997). A study of the performance of patients with frontal lobe lesions in a financial planning task. Brain, 120, 1805-1822.

Goel, V., \& Vartanian, O. (2005). Dissociating the roles of right ventral lateral and dorsal lateral prefrontal cortex in generation and maintenance of hypotheses in set-shift problems. Cerebral Cortex, 15, 1170-1177.

Goodman, W. K., Price, L. H., Rasmussen, S. A., Mazure, C., FleischManN, R. L., Hill, C. L., ET AL. (1989). The Yale-Brown Obsessive Compulsive Scale: I. Development, use, and reliability. Archives of General Psychiatry, 46, 1006-1011.

Grant, J. E., \& Potenza, M. N. (2006). Compulsive aspects of impulse-control disorders. Psychiatric Clinics of North America, 29, 539-551.

Guilford, J. P., Christensen, P. R., Merrifield, P. R., \& WilSON, R. C. (1978). Alternate uses: Manual of instructions and interpretation. Orange, CA: Sheridan Psychological Services.

Hajcak, G., Huppert, J. D., Simons, R. F., \& Foa, E. B. (2004). Psychometric properties of the OCI-R in a college sample. Behaviour Research \& Therapy, 42, 115-123.

Hare, R. M. (1963). Backsliding. In Freedom and reason (pp. 67-86). Oxford: Oxford University Press.

Heckhausen, H. (1991). Motivation and action. New York: Springer.

Heckhausen, H., \& Gollwitzer, P. M. (1987). Thought contents and cognitive functioning in motivational versus volitional states of mind. Motivation \& Emotion, 11, 101-120.

Hollis, M. (1994). The philosophy of social science: An introduction. Cambridge: Cambridge University Press.

HoOKer, B., \& STREumer, S. (2004). Procedural and substantive practical rationality. In A. R. Mele \& P. Rawling (Eds.), The Oxford handbook of rationality (pp. 57-74). Oxford: Oxford University Press.

Huettel, S. A., Stowe, C. J., Gordon, E. M., Warner, B. T., \& Platt, M. L. (2006). Neural signatures of economic preferences for risk and ambiguity. Neuron, 49, 765-775.

Jamison, K. R. (1995). Manic-depressive illness and creativity. Scientific American, 272, 62-67.

Kaiser, S., Roth, A., Rentrop, M., Friederich, H.-C., Bender, S., \& WeIsBrod, M. (2008). Intra-individual reaction time variability in schizophrenia, depression and borderline personality disorder. Brain \& Cognition, 66, 73-82.

Kennett, J., \& Smith, M. (1994). Philosophy and commonsense: The case of weakness of will. In M. Michael \& J. O'Leary-Hawthorne (Eds.), Philosophy in mind: The place of philosophy in the study of mind (pp. 141-157). Dordrecht, The Netherlands: Kluwer Academic Publishers.

KLeIN, G., \& Wolf, S. (1998). The role of leverage points in option generation. IEEE Transactions on Systems, Man, \& Cybernetics C, 28, 157-160.

Knutson, B., \& Peterson, R. (2005). Neurally reconstructing expected utility. Games \& Economic Behavior, 52, 305-315.

Konishi, S., NaKaJima, K., Uchida, I., Sekihara, K., \& MiYashita, Y. (1998). No-go dominant brain activity in human inferior prefrontal cortex revealed by functional magnetic resonance imaging. European Journal of Neuroscience, 10, 1209-1213.

Kraepelin, E. (1919). Dementia praecox and paraphrenia. New York: Krieger.

Kropotov, J. D., \& Etlinger, S. C. (1999). Selection of actions in the basal ganglia-thalamocortical circuits: Review and model. International Journal of Psychophysiology, 31, 197-217.

Kwapil, T. R., Raulin, M. L., \& MidThun, J. C. (2000). A ten-year longitudinal study of intense ambivalence as a predictor of risk for psychopathology. Journal of Nervous \& Mental Disease, 188, 402-408.

Lau, H. C., Rogers, R. D., Haggard, P., \& Passingham, R. E. (2004). Attention to intention. Science, 303, 1208-1210.

Lawrence, N. S., Wooderson, S., Mataix-Cols, D., David, R., SpeckENS, A., \& PHILlips, M. L. (2006). Decision-making and set shifting impairments are associated with distinct symptom dimensions in obsessive-compulsive disorder. Neuropsychology, 20, 409-419.

Lejoyeux, M., Feuché, N., Loi, S., Solomon, J., \& AdÈs, J. (1999). Study of impulse-control disorders among alcohol-dependent patients. Journal of Clinical Psychiatry, 60, 302-305. 
Levy, R., \& Dubois, B. (2006). Apathy and the functional anatomy of the prefrontal cortex-basal ganglia circuits. Cerebral Cortex, 16, 916-928.

Lezak, M. D., Howieson, D. B., Loring, D. W., Hannay, H. J., \& FISCHER, J. S. (2004). Neuropsychological assessment (4th ed.). Oxford: Oxford University Press

LI, C. R., \& CHEN, S.-H. (2007). Obsessive-compulsiveness and impulsivity in a nonclinical population of adolescent males and females. Psychiatry Research, 149, 129-138.

Libet, B., Gleason, C. A., Wright, E. W., \& Pearl, D. K. (1983). Time of conscious intention to act in relation to onset of cerebral activity (readiness-potential): The unconscious initiation of a freely voluntary act. Brain, 106, 623-642.

Logan, G. D., Schachar, R., \& TANNOCK, R. (1997). Impulsivity and inhibitory control. Psychological Science, 8, 60-64.

Macmillan, M. (2000). An odd kind of fame: Stories of Phineas Gage. Cambridge, MA: MIT Press.

Marin, R. S. (1996). Apathy: Concept, syndrome, neural mechanisms, and treatment. Seminars in Clinical Neuropsychiatry, 1, 304-314.

Marin, R. S., BiedrzYCKI, R. C., \& Firinciogullari, S. (1991). Reliability and validity of the Apathy Evaluation Scale. Psychiatry Research, 38, 143-162.

McClure, S. M., Laibson, D. I., Loewenstein, G., \& Cohen, J. D (2004). Separate neural systems value immediate and delayed monetary rewards. Science, 306, 503-507.

McINTYRE, A. (1990). Is akratic action always irrational? In O. Flanagan \& A. A. O. Rorty (Eds.), Identity, character, and morality: Essays in moral psychology (pp. 379-400). Cambridge, MA: MIT Press.

MeEhl, P. E. (1962). Schizotaxia, schizotypy, schizophrenia. American Psychologist, 17, 827-838

Mega, M. S., \& Cummings, J. L. (1994). Frontal-subcortical circuits and neuropsychiatric disorders. Journal of Neuropsychiatry \& Clinical Neurosciences, 6, 358-370.

Mele, A. R. (1987). Irrationality: An essay on akrasia, self-deception, and self-control. New York: Oxford University Press.

Mele, A. R. (2002). Akratics and addicts. American Philosophical Quarterly, 39, 153-167.

Metzinger, T. (2006). Conscious volition and mental representation: Toward a more fine-grained analysis. In N. Sebanz \& W. Prinz (Eds.), Disorders of volition (pp. 19-48). Cambridge, MA: MIT Press.

Moeller, F. G., Barratt, E. S., Dougherty, D. M., Schmitz, J. M., \& Swann, A. C. (2001). Psychiatric aspects of impulsivity. American Journal of Psychiatry, 158, 1783-1793.

Mostofsky, S. H., \& Simmonds, D. J. (2008). Response inhibition and response selection: Two sides of the same coin. Journal of Cognitive Neuroscience, 20, 751-761.

Muraven, M., \& Baumeister, R. F. (2000). Self-regulation and depletion of limited resources: Does self-control resemble a muscle? Psychological Bulletin, 126, 247-259.

NAchev, P. (2006). Cognition and medial frontal cortex in health and disease. Current Opinion in Neurology, 19, 586-592.

Nathan, P. E., \& Langenbucher, J. W. (1999). Psychopathology: description and classification. Annual Review of Psychology, 50, 79107.

Nordgren, L. F., van Harreveld, F., \& Van der Pligt, J. (2006). Ambivalence, discomfort, and motivated information processing. Journal of Experimental Social Psychology, 42, 252-258.

Obsessive Compulsive Cognitions Working Group (1997). Cognitive assessment of obsessive-compulsive disorder. Behaviour Research \& Therapy, 35, 667-681.

Passingham, R. E. (1995). The frontal lobes and voluntary action. Oxford: Oxford University Press

Patton, J. H., Stanford, M. S., \& Barratt, E. S. (1995). Factor structure of the Barratt Impulsiveness Scale. Journal of Clinical Psychology, 51, 768-774

Perkins, D. N. (2002). The engine of folly. In R. J. Sternberg (Ed.), Why smart people can be so stupid (pp. 64-85). New Haven, CT: Yale University Press.

Pettit, P., \& Smith, M. (1993). Practical unreason. Mind, 102, 53-79.

RAAB, M., \& Johnson, J. G. (2007). Expertise-based differences in search and option-generation strategies. Journal of Experimental Psychology: Applied, 13, 158-170.

Rahman, S., Sahakian, B. J., Cardinal, R. N., Rogers, R. D., \& Rob-
BINS, T. W. (2001). Decision-making and neuropsychiatry. Trends in Cognitive Sciences, 5, 271-277.

Rao, V., Spiro, J. R., Schretlen, D. J., \& Cascella, N. G. (2007). Apathy syndrome after traumatic brain injury compared with deficits in schizophrenia. Psychosomatics, 48, 217-222.

RAZ, J. (2005). The myth of instrumental rationality. Journal of Ethics \& Social Philosophy, 1, 2-28.

Rentrop, M., Backenstrass, M., Jaentsch, B., Kaiser, S., Roth, A., UNGER, J., ET AL. (2007). Response inhibition in borderline personality disorder: Performance in a go/no-go task. Psychopathology, 41, 50-57.

Reuter, B., Jäger, M., Bottlender, R., \& Kathmann, N. (2007). Impaired action control in schizophrenia: The role of volitional saccade initiation. Neuropsychologia, 45, 1840-1848.

Revheim, N., Schechter, I., Kim, D., Silipo, G., Allingham, B., ButLER, P., \& JAVITT, D. C. (2006). Neurocognitive and symptom correlates of daily problem-solving skills in schizophrenia. Schizophrenia Research, 83, 237-245.

REYNOLDS, B. (2006). A review of delay-discounting research with humans: Relations to drug use and gambling. Behavioural Pharmacology, 17, 651-667.

Rogers, R. D., Everitt, B. J., Baldacchino, A., Blackshaw, A. J., Swainson, R., Wynne, K., ET AL. (1999). Dissociable deficits in the decision-making cognition of chronic amphetamine abusers, opiate abusers, patients with focal damage to prefrontal cortex, and tryptophan-depleted normal volunteers: Evidence for monoaminergic mechanisms. Neuropsychopharmacology, 20, 322-339.

RorTy, A. O. (1985). Self-deception, akrasia and irrationality. In J. Elster (Ed.), The multiple self (pp. 115-131). Cambridge: Cambridge University Press. (Original work published in 1980)

RorTy, A. O. (1988). Where does the akratic break take place? In Mind in action: Essays in the philosophy of mind (pp. 229-270). Boston: Beacon Press. (Original work published in 1980)

Roth, R. M., Koven, N. S., Pendergrass, J. C., Flashman, L. A., MCAllister, T. W., \& SAYKIN, A. J. (2008). Apathy and the processing of novelty in schizophrenia. Schizophrenia Research, 98, 232-238.

Sanfey, A. G., Loewenstein, G., McClure, S. M., \& Cohen, J. D. (2006). Neuroeconomics: Cross-currents in research on decisionmaking. Trends in Cognitive Sciences, 10, 108-116.

Schneider, W. X. (2006). Action control and its failure in clinical depression. In N. Sebanz \& W. Prinz (Eds.), Disorders of volition (pp. 275-306). Cambridge, MA: MIT Press.

SCHWEIZER, T. S. (2006). The psychology of novelty-seeking, creativity and innovation: Neurocognitive aspects within a work-psychological perspective. Creativity \& Innovation Management, 15, 164-172.

SEARLE, J. R. (2001). Weakness of will. In Rationality in action (pp. 219237). Cambridge, MA: MIT Press.

Seitz, R. J., Stephan, K. M., \& Binkofski, F. (2000). Control of action as mediated by the human frontal lobe. Experimental Brain Research, 133, 71-80.

Semkovska, M., Stip, E., Godbout, L., Paquet, F., \& Bédard, M. A. (2002). Behavioral disorganization in schizophrenia during a daily activity: The kitchen behavioral scoring scale. Brain \& Cognition, 48, 546-553.

Simmonds, D. J., Pekar, J. J., \& Mostofsky, S. H. (2008). Metaanalysis of go/no-go tasks demonstrating that fMRI activation associated with response inhibition is task-dependent. Neuropsychologia, 46, 224-232.

Simon, H. A. (1973). The structure of ill-structured problems. Artificial Intelligence, 4, 181-201.

Smith, M. (2003). Rational capacities, or: How to distinguish recklessness, weakness, and compulsion. In S. Stroud \& C. Tappolet (Eds.), Weakness of will and practical irrationality (pp. 17-38). Oxford: Oxford University Press.

Sobin, C., MaYer, L., \& Endicott, J. (1998). The Motor Agitation and Retardation Scale: A scale for the assessment of motor abnormalities in depressed patients. Journal of Neuropsychiatry \& Clinical Neurosciences, 10, 85-92.

Sockeel, P., Dujardin, K., Devos, D., Denève, C., Destée, A., \& Defebvre, L. (2006). The Lille Apathy Rating Scale (LARS), a new instrument for detecting and quantifying apathy: Validation in Parkinson's disease. Journal of Neurology, Neurosurgery, \& Psychiatry, 77, 579-584.

Sorensen, R. (2004). Paradoxes of rationality. In A. R. Mele \& P. Rawl- 
ing (Eds.), The Oxford handbook of rationality (pp. 257-278). Oxford: Oxford University Press.

Spence, S. A., \& Parry, C. (2006). In N. Sebanz \& W. Prinz (Eds.), Disorders of volition (pp. 207-232). Cambridge, MA: MIT Press.

Spencer, T. J., Biederman, J., \& Mick, E. (2007). Attention-deficit/ hyperactivity disorder: Diagnosis, life span, comorbidities, and neurobiology. Journal of Pediatric Psychology, 32, 631-642.

STOCKer, M. (1979). Desiring the bad: An essay in moral psychology. Journal of Philosophy, 76, 738-753.

Stroud, S., \& TAPpolet, C. (2003). Introduction. In S. Stroud \& C. Tappolet (Eds.), Weakness of will and practical irrationality (pp. 1-16). Oxford: Oxford University Press.

Takizawa, R., Kasai, K., Kawakubo, Y., Marumo, K., Kawasaki, S., YAMASUE, H., \& FUKUDA, M. (2008). Reduced frontopolar activation during verbal fluency task in schizophrenia: A multichannel nearinfrared spectroscopy study. Schizophrenia Research, 99, 250-262.

Tenenbaum, S. (2003). Accidie, evaluation, and motivation. In S. Stroud \& C. Tappolet (Eds.), Weakness of will and practical irrationality (pp. 147-171). Oxford: Oxford University Press.

Tobler, P. N., O’Doherty, J. P., Dolan, R. J., \& Schultz, W. (2007). Reward value coding distinct from risk attitude-related uncertainty coding in human reward systems. Journal of Neurophysiology, 97, 1621-1632.

Tom, S. M., Fox, C. R., Trepel, C., \& Poldrack, R. A. (2007). The neural basis of loss aversion in decision-making under risk. Science, 315, 515-518.

ToRrance, E. P. (1990). Torrance tests of creative thinking. Bensenville, IL: Scholastic Testing Service.

VARTANian, O., \& Goel, V. (2005). Task constraints modulate activation in right ventral lateral prefrontal cortex. NeuroImage, 27, 927-933.
WALSH, D. (1975). “Akrasia” reconsidered. Ethics, 85, 151-158.

Watson, G. (1977). Skepticism about weakness of will. Philosophical Review, 86, 316-339.

Widiger, T. A., \& SANKIS, L. M. (2000). Adult psychopathology: Issues and controversies. Annual Review of Psychology, 51, 377-404.

Wittmann, M., \& Paulus, M. P. (2008). Decision making, impulsivity and time perception. Trends in Cognitive Sciences, 12, 7-12.

Yacubian, J., Gläscher, J., Schroeder, K., Sommer, T., Braus, D. F., \& BüCHEL, C. (2006). Dissociable systems for gain- and loss-related value predictions and errors of prediction in the human brain. Journal of Neuroscience, 26, 9530-9537.

Zermatten, A., Van der Linden, M., D'Acremont, M., Jermann, F., \& Bechara, A. (2005). Impulsivity and decision-making. Journal of Nervous \& Mental Disease, 193, 647-650.

\section{NOTE}

1. In a different philosophical context, this concept of ambivalence has been discussed in terms of a dilemma called "Buridan's ass." This is the dilemma faced by an ass that finds itself presented with two equidistant and equally attractive bales of hay. As choices are supposedly made on the basis of preferences, the ass cannot choose because he has an equal preference for both bales. He therefore chooses neither bale of hay and starves (Sorensen, 2004).

(Manuscript received March 17, 2008; revision accepted for publication July 10, 2008.) 